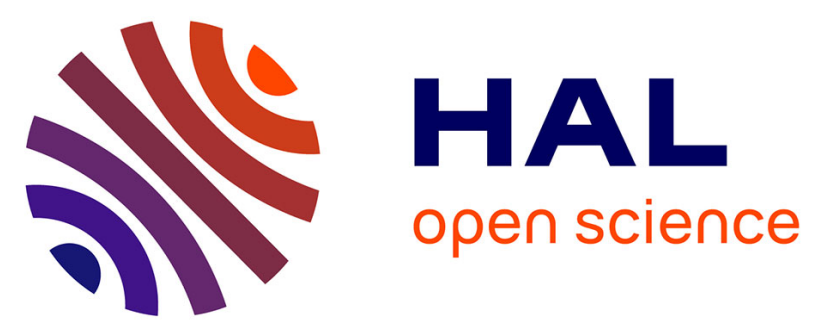

\title{
Consequences to water suppliers of collecting rainwater on housing estates
}

Auguste Gires, Bernard de Gouvello

\section{To cite this version:}

Auguste Gires, Bernard de Gouvello. Consequences to water suppliers of collecting rainwater on housing estates. Water Science and Technology, 2009, 60 (3), pp.543-553. hal-00816788

\section{HAL Id: hal-00816788 \\ https://hal-enpc.archives-ouvertes.fr/hal-00816788}

Submitted on 8 Apr 2016

HAL is a multi-disciplinary open access archive for the deposit and dissemination of scientific research documents, whether they are published or not. The documents may come from teaching and research institutions in France or abroad, or from public or private research centers.
L'archive ouverte pluridisciplinaire HAL, est destinée au dépôt et à la diffusion de documents scientifiques de niveau recherche, publiés ou non, émanant des établissements d'enseignement et de recherche français ou étrangers, des laboratoires publics ou privés. 


\section{Consequences to water suppliers of collecting rainwater on}

\section{housing estates}

Auguste Gires (auguste.gires@cereve.enpc.fr) (1) ; Bernard de Gouvello (1,2)

(1) Université Paris-Est, Leesu, UMR MA 102 AgroParisTech, 6-8 avenue Blaise

Pascal, F 77455 Marne la Vallée cedex 2

(2) Centre scientifique et technique du bâtiment, 84 av Jean Jaurès, F 77421 Marne la Vallée

Cedex 2

\section{$\underline{\text { Abstract }}$}

The collection, storage and use of rainwater from roofs reduce the need for potable water. However if water suppliers are to decrease their infrastructure costs as well as their operational costs (due to water savings), the rainwater system has to provide most of the time a significant percentage of the water demand. This paper adopts the view point of the water suppliers and investigates how reliable this source of water is in the case of a housing estate, considering WC flushing as the only water demand. A housing estate was modelled and different realistic input scenarios (water demand for WC flushing, storage capacity, roof area, and rainfall) were defined. Three indicators were exhibited. The variability generated by each input on the indicators was evaluated. The indicators were estimated for 63 homogeneously distributed French cities. Among the indicators exhibited in this paper, the most relevant one is the percentage of water supplied from the tank that is secured during $95 \%$ of the days of the

23 simulation. The main conclusion is that the optimum way of determining the storage capacity 
the viewpoint of the water suppliers. Indeed, water suppliers tend to require bigger tanks in order to take into account the rainwater collection systems in their management plan.

$\underline{\text { Key words: }}$ Rainwater collection, Modelling, Simulation, Water conservation, water utility management

\section{Introduction}

In the debate on sustainable water management, a growing place is given to rainwater. Rainwater tends to be considered more and more as a potential source to supply water to not only small isolated areas, but also existing towns or new urban projects. In many developing and developed countries such as Brazil (Ghisi, 2005; 2006), West Africa (Cowaken, 2008), Australia (Coombes, 1999) or Germany (Hermann, 1999; Nolde, 2007), rainwater harvesting and use within the building is already a widespread practice.

In France, despite a very restrictive regulatory framework limiting the use of rainwater to outdoor activities, this practice also started to grow from 2000 (de Gouvello et al., 2005). In 2008, a new specific regulation framework was sketched, authorising the use of rainwater within the building for several non potable uses: WC, floor cleaning and - under conditions still to be defined - washing machines. This new framework will foster the development of this practice and may have consequences on the water utilities' supply management. Several tools were developed to quantify these consequences. For instances Aquacycle (Mitchell, 2001), which is based on the concept of water balance of the urban water cycle permits to estimate the feasibility of alternative water management options and evaluate the performance of a re-use scheme, at different scales (Unit block, cluster, or catchment). An enhanced version, called Urban Volume and Quantity (Mitchell, 2003), that includes new flow paths 


\section{列}

and a contaminant balance model, was developed. The Probabilistic Urban Rainwater and wastewater Reuse Simulator (PURRS) by Coombes and Kuczera (2001) operates at 6 minute time steps to simulate and evaluate the efficiency of a reuse scheme.

Nevertheless, these models only highlight the overall performance of water management options. This paper suggests adopting the viewpoint of the water supplier and introduces new indicators evaluating the daily reliability of rainwater as a source of water. These indicators are relevant at a regional scale, that is to say a scale that includes the water treatment plant, the distribution network and the consumer. The sensitivity of these new indicators to each input was analysed. They were tested for 63 French cities in order to exhibit disparities. This paper focuses on the specific case of housing estates, as it seems to be a trouble-free area to equip with rainwater collection systems, since there is room to install the tanks and the roof area available per person is much greater than in denser parts of the city.

\section{Model description and data}

The aim of this paper is to analyse the behaviour of a housing estate in which all plots are equipped with rainwater collecting systems. In this paper, only the effects of individual systems are considered and collective systems (such as shared rainwater tanks) are not modelled. This housing estate model is more than a plot model multiplied by the number of plots since the features -and consequently the behaviour- of each plot will be different to better represent the real situation. Since this paper studies rainwater collection systems from the point of view of the water suppliers, we analyse the behaviour and define indicators for the whole housing estate and not only the behaviour of each plot.

\subsection{Behaviour model of the rainwater collection system}


In essence, a rainwater collection system works as described in Fig 1. The rainwater harvested by the catchment area (here the roof of the house) goes into a tank where it is stored until it is withdrawn to meet the water demand. If the volume exceeds the storage capacity, the runoff is overflowed elsewhere (sewage system, retention device...) and lost for usage. If the tank does not supply enough water to meet the demand, then the water is withdrawn from the water supply distribution network. collecting system during a given time interval. The yield after spillage (YAS) algorithm, in which the withdrawal occurs before the rainfall, is

$$
\begin{gathered}
Y_{n}=\min \left\{\begin{array}{c}
D_{n} \\
V_{n-1}
\end{array}\right\}(1) \\
V_{n}=\min \left\{\begin{array}{c}
V_{n-1}+R_{n}-Y_{n} \\
S-Y_{n}
\end{array}\right\}
\end{gathered}
$$

where $R_{n}$ is the volume of rainwater captured $\left(\mathrm{m}^{3}\right)$ during time interval $n$ (which is equal to the rainfall $(\mathrm{m})$ during the time interval $\mathrm{n}$ multiplied by the roof area $\left(\mathrm{m}^{2}\right)$, neglecting any potential initial losses), $V_{n}$ is the water volume in the tank $\left(\mathrm{m}^{3}\right)$ during time interval $n, Y_{n}$ is the yield $\left(\mathrm{m}^{3}\right)$ during time interval $\mathrm{n}, \mathrm{D}_{\mathrm{n}}$ is the demand during time interval $\mathrm{n}$, and $\mathrm{S}$ is the storage capacity $\left(\mathrm{m}^{3}\right)$.

The yield before spillage (YBS), in which the withdrawal occurs after the rainfall is

$$
\begin{gathered}
Y_{n}=\min \left\{\begin{array}{c}
D_{n} \\
V_{n-1}+R_{n}
\end{array}\right\} \\
V_{n}=\min \left\{\begin{array}{c}
V_{n-1}+R_{n}-Y_{n} \\
S
\end{array}\right\}
\end{gathered}
$$


The YAS algorithm under evaluates the amount of water provided by the rainwater collection system, whereas YBS algorithm over evaluates it since there is less water in the tank to match the demand. In this investigation, each simulation was tested with both algorithms and the values obtained for the indicators were always similar. Therefore in this paper, the given value of an indicator corresponds to the mean of the values obtained from the

101 simulations made with the YAS and the YBS algorithms. Fewkes and Butler (2000) recommend using a daily model for a storage fraction (eg. the storage capacity of the tank divided by the rainwater captured in a year) belonging to the range $0.01-0.125^{1}$. Since the average storage fraction of the simulations carried out in this paper is 0.026 , a daily model lasting five years has been used. It has to be mentioned that

106 Coombes (2007a) showed that the use of 6 minute time steps lead to a better efficiency of the

107 collecting systems. This effect is likely to be at least partly compensated by the use of the mean results of the YAS and YBS algorithms.

110 performed.

\subsection{Realistic modelling of a housing estate}

115 area, and the storage capacity were determined for each plot. In order to evaluate the 116 variability created by each input, several scenarios were made.

\footnotetext{
${ }^{1}$ A smaller storage fraction would imply the use of an hourly time interval, and a bigger one would authorize the use of a monthly model.

${ }^{2}$ A free scientific software package developed under the responsibility of a consortium that includes INRIA, the French national institute for computer science.
} 
The only water demand considered in this paper is WC flushing. In this simulation, the variability of the demand through the week was taken into account and not just the average demand. The average demand was determined from the C.I.Eau (Water information centre, a

121 French association of the main water suppliers, which collects and publishes data on water).

122 Data, which shows that WC flushing accounts for approximately $20 \%$ of the total domestic 123 water demand of 137 litres per person per day. The average demand for WC flushing is 124 therefore $27.4 \mathrm{1} /$ person/day. Using the distribution data implemented by the experiment 125 MARIA lead by the CSTB (de Gouvello et al., 2005), it has been possible to distribute the 126 demand according to the day of the week. The demand considered per person per day is 241 127 during the week, 37.71 on Saturday, and 34.21 on Sunday. In the following sections of the 128 paper, various scenarios were made, considering a range of 1 to 6 occupants per plot. A 129 realistic distribution of people according to the plot was required. The INSEE (the French 130 national institute of statistics) data from the 1999 census of the French population was used.

131 The figures are only available for cities, so it was necessary to select cities that have a 132 homogenous pattern (mainly housing estate areas and very few buildings). City patterns were 133 checked using satellite images. Since the distribution of inhabitants of the cities having the 134 correct features did not exhibit (for the thirteen selected cities) clear regional tendency, i.e. the 135 regional differences are comparable to the differences between cities in the suburb of the 136 same larger one, it was decided to select only two cities, of which the inhabitants distributions 137 are displayed in Tab 1. These two cities were chosen because they represent two different 138 kinds of inhabitants' distribution: Vendeville (North of France, in the suburb of Lille) is a city 139 where there are mainly families (more than half of the houses are occupied by three or more 140 people) whereas Génémos (South of France, in the suburb of Marseilles) is a city where there 141 are mainly single persons or couples (more than half of the houses are occupied by one or two 
142 people). In this paper we refer to Vendeville as the family option, and Génémos as the couple

143 option.

Since this paper adopts the viewpoint of the water supplier, that is to say what it definitely expects, the storage capacities are not optimised according to the region as it was

147 done in previous studies (Coombes; 2007b; Aquacycle users guide; 2005). Several realistic 148 scenarios were built for the sizes of the tanks using the following methodology, which is based on the householders' needs. In the experiment of MARIA lead by the CSTB in Champs-sur-Marne (about $25 \mathrm{~km}$ from Paris), de Gouvello et al. (2005) showed that a storage capacity that corresponds to approximately 4 weeks of the water demand is almost always enough to ensure the autonomy of the installation. It has been shown that this ratio is only an optimum for customers in the region of Paris. Nevertheless it is adopted for all French cities, knowing that it might not always be optimum for the customer. Yet the results obtained here show that this ratio works all over France. In the following sections of the paper, several scenarios were made knowing that people will not necessarily choose the optimum storage capacity (saving money, change of owner, birth, departure of a child...). Since the number of

158 people per plot ranges from 1 to 6 , the storage capacity chosen in this paper ranges from 0.5 to $4 \mathrm{~m}^{3}{ }^{3}$ As the daily rainfall time series used in the simulations last for a duration of 5 years,

160 it is not necessary to have different starting configurations for the tank. Indeed they will all be 161 notably full after the first major rainfall or notably empty after the first drought period.

162 The only catchment area considered in this paper is the roof. An average projected 163 roof area of $100-120 \mathrm{~m}^{2}$ was estimated by observing Google Earth images of the selected 164 cities used to model the distribution of people according to the plot. The roof area chosen in 165 the scenarios of the following sections ranges from 60 to $160 \mathrm{~m}^{2}$.

\footnotetext{
${ }^{3}$ The considered storage capacity in this paper are $0.5 ; 0.75 ; 1.3 ; 2 ; 3$ and $4 \mathrm{~m}^{3}$
} 

(1994-1998). Series for 63 French cities were used. A time series lasting 30 years (19762005) for Paris was also available and tested. The distribution of cities in France is quite homogenous, so it can be considered that they are representative of the climates in France over a period of five years.

\section{Towards the definition of relevant indicators}

173

The usual indicator (Fewkes, 2000) used to evaluate the performance of a rainwater collecting system is the water-saving efficiency (E). It is equal to the percentage of the overall demand of the WC flushing supplied by the tank during $\mathrm{N}$ time intervals. It is given by the following equation:

$$
E=\frac{\sum_{n=1}^{N} Y_{n}}{\sum_{n=1}^{N} D_{n}} * 100(5)
$$

This indicator is interesting for the consumer since it determines whether the collection system is efficient and beneficial. It also permits to estimate the possible savings in energy (pumping, treatments ...) that the water supplier can expect in operational costs (Coombes, 2007). However it does not give any information on the regional impact of a generalised rainwater collection on the infrastructure costs (size of the pipes, the pumps, the water treatment works, ...). To be able to decrease the latter costs, water suppliers need to evaluate the reliability of this source of water. If ever the systems do not supply enough water to meet the demand, the supplier will be expected to do so and therefore should not reduce the size of its infrastructure. To estimate this reliability, the authors suggest using a "reliability curve", which is drawn for each simulation. Refer to Fig 2 for an example. To read this curve, 
a percentage of water volume supplied by the tank is chosen on the vertical axis, and the

190 corresponding value on the horizontal axis gives the proportion of days when this percentage 191 is reached.

From this curve, three reliability indicators (RI) are estimated:

- RI1: the percentage of days the tank supplies $100 \%$ of the demand for WC flushing.

195 This indicator was also analysed for $95 \%$ and $90 \%$. The value $100 \%$ was chosen because it generated the indicator with the highest sensitivity among the French cities, making it the most relevant. This indicator corresponds to the "event reliability" used in Aquacycle (Users guide, 2005). On the curve in Fig 2, RI1 is equal to $58 \%$.

- RI2: the percentage of days the tank supplies less than $10 \%$ of the water demand. It was also studied with $5 \%$ and $0 \%$, but the sensitivity among the French cities was greater for the value of $10 \%$. On the curve in Fig 2, RI2 is equal to $3 \%$.

- RI3: the percentage of water supplied by the tank over $95 \%$ of the days of the simulation. To estimate this, the daily water-saving efficiency $\left(Y_{n} / D_{n}\right)$ is evaluated for all the days of the series. RI3 is the lowest daily water-saving efficiency. This indicator was also analysed for $90 \%$ and $100 \%$. The value $95 \%$ was chosen because it generated the indicator with the highest sensitivity amongst the French cities, making it the most relevant. On the curve in Fig 2, RI3 is equal to $24 \%$.

Even though all the indicators are percentages, it is important to note that the first two are percentages of days, whereas the third is a percentage of water demand supplied. If RI1 is too small or RI2 too great, it implies that the water supplier will not be able to decrease their

211 infrastructure costs because rainwater is not a reliable enough source of water. RI3 gives an 212 idea of the possible reliable demand reduction. For example if RI3 is equal to $20 \%$ then the 213 water supplier can expect a reduction in the water demand of $4 \%$ (the WC flushing usage 
represents $20 \%$ of the potable household water usage in France) with very limited risks for its customers.

\section{Results and discussion}

In the first part of this section the sensitivity of the indicators for each input is evaluated. This is done by analysing the variability generated on the indicators when the input scenarios change. This allows defining relevant scenarios to estimate the indicators for 63 French cities. An analysis of the values of the indicator in France was then performed.

\subsection{Analysing the sensitivity}

\subsubsection{Methodology of investigation}

In order to evaluate the variability generated by each input, seven options were tested for each input on a housing estate consisting of ten plots. Since a scenario is defined from different combinations of the inputs, a total of $2401(=7 * 7 * 7 * 7)$ scenarios were tested. The options, based on the values found in the first section, are presented in Fig 3. Since the aim is

232 to estimate the variability, some of the chosen options may not look very realistic. Concerning 233 the chosen rain sites, they are homogeneously distributed over the French territory, which 234 permits to have a set of different French climates. Then the four indicators were estimated via 235 a computer coded simulation for each set of options. The results were put in arrays E, RI1, $236 \mathrm{RI}$, and RI3, whose sizes are $7 * 7 * 7 * 7$. In the following, the chosen rain option is represented 237 by the index $\mathrm{i}$, the inhabitant option by $\mathrm{j}$, the roof area option by $\mathrm{k}$, and the store capacity 238 option by 1. 
The same method was used to analyse the variability of each indicator, and is 241 described here for the indicator RI1. It consists in keeping three inputs constant while the 242 fourth changes. For instance, the rain_standard_deviation array (whose size is $7 * 7 * 7$ ) was 243 evaluated to analyse the input "rain". The term $(\mathrm{j}, \mathrm{k}, \mathrm{l})$ of this array is the standard deviation of 244 the set $\{R I 1(i, j, k, l), i \in\{1,2, . .7\}\}$. Then the average variability generated by the rain on the 245 RI1 indicator is the mean of this array. In order to evaluate the reliability of this average 246 variability, the standard deviation of the array was also evaluated. If it is too great compared 247 to the average variability, it means that this average variability is not very reliable. The same procedure was then followed for each input.

\subsubsection{Variability created by each input}

The results for the variability generated by each input are shown in Tab 2 .

First of all, it can be noted that the variability generated by the rain is the most important, which is one of the reasons why a geographical analysis was performed and is explained in the next section. The duration ( 5 years) of the rainfall time series did not permit to perform a temporal analysis of the evolution of these indicators for a given city. The variability created by the various distributions of inhabitants is quite important. However the chosen options were quite extreme and the actual repartition is more homogenous so in reality, this input will not create much variability. The roof area is the input that generates the less variability. This is due to the fact, that when it rains, it often rains more than necessary to

262 fill the tank, so that even a small roof fills the rainwater collection system. The variability 263 generated by the storage capacity is important, which confirms (Lucas, 2006) that people 
264 should be very careful when they are choosing the optimum size of their tank. The disparities 265 existing among the different scenarios are highest for RI3. This will be confirmed in the next 266 section as a geographical analysis shows great disparities among the cities, making RI3 a very 267 relevant indicator to distinguish between the sites.

These values of average variability must be considered very carefully because their reliability is not very good. This is due to the fact that there are many disparities between the chosen options to perform the investigation. Since the averaged variability is often quite high, a more precise analysis is required to decide whether the water supplier can take the existence of rainwater collection systems into account in their management plan. This is explained in 273 the next section.

\subsection{Results for 63 French Cities}

As explained in the previous section it is not possible to give a unique answer to whether water suppliers can take into account a water demand reduction in their management plan if there is a generalised installation of rainwater collection system.

In this section a geographical analysis was performed. Several realistic options were defined for each input on a housing estate consisting of 100 plots, so that the estimated figures are reliable. These options are presented in Fig 4. Since the variability generated by the 284 inhabitants is not substantial, only two options were considered for the number of occupants, 285 whereas three were considered for the storage capacity. Only one was considered for the roof 286 area since this input does not generate much variability. As a geographical analysis is performed the only rain option considered is the daily rainfall time series of the considered 
city. This means that for each city $6(=2 * 1 * 3 * 1)$ scenarios were considered. The average RI1,

289 RI2, and RI3 were figured for 63 French cities.

For each indicator the mean, the standard deviation, the minimum and the maximum are presented in Tab 3. First of all, the average $\mathrm{E}$ is $93.5 \%$, with a small standard deviation of $5.3 \%$, confirming that the storage capacity determined all over France with the help of an optimum in the region of Paris, is correct. However we can note that it might be slightly undersized for some cities since the minimum is $75.1 \%$. As it can be seen RI1 ranges from $45.6 \%$ to $86.5 \%$, which means that this indicator is relevant to exhibit disparities and that the water suppliers can consider it will not be smaller than $40 \%$. The map of this indicator is presented in Fig 5. RI2 ranges from 0.1 to 10.2 according to the city. This shows that even if this indicator remains interesting for the water supplier, since it can be considered to always be a low value, there are no big disparities among the French cities, so a map of this indicator was not included in this paper. Concerning RI3, the value ranges from 6.2 to 93.8 which makes this indicator a very relevant way to compare the cities according to the reliability of 303 the water supplied by a collection system. This is why we are going to focus our analysis on 304 this indicator. The map of this indicator in France is presented in Fig 5. Fig 6 presents RI3 for each city, sorted in order according to increasing values of RI3.

The 30 year long time series over Paris was split into 6 series of 5 years each. All indicators were assessed for each period, and the main statistics are displayed on table 4 . The 308 standard deviation generated by the temporal differences (tab 4) is much smaller than the one

309 generated by the spatial differences of rain (tab 3). This means that figures 5 and 6 remain 310 relevant despite using rainfall time series lasting only 5 years. Nevertheless further 311 investigations would require the use of longer series to achieve more robust results. 
It is worth noting that the pattern shown in Fig 6 may be representative of the French territory. An analysis with more cities would permit to confirm this. With the help of Fig 6, it is possible to define three clusters of cities: not reliable (RI3 ranges from $0 \%$ to $50 \%$ ), reliable (RI3 ranges from 50\% to $70 \%$ )), and highly reliable (RI3 ranges from $70 \%$ to $100 \%$ ). These clusters permit to define 5 areas in France (shown in Fig 5), which appear to be stratified according to a direction South-West, North-East:

- $\quad 1$ and 3 : these areas are highly reliable

- 2: the disparities among cities that are close together do not permit to exhibit a clear tendency. Rainfall series from more cities would be required to make a deeper analysis.

- 4: this area is reliable. It is between a highly reliable area and an unreliable area, which means that the evolution of the indicators whilst moving from South-East to North-West appears to be continuous.

$\mathrm{E}$ is almost always a high value and does not exhibit a lot of disparities in France, whereas RI3 varies in a wide range of figures. This means that the optimum way of determining the storage capacity of the rainwater collection system is not the same if you 331 adopt the viewpoint of the customers or if you adopt the water suppliers'. Indeed the water 332 suppliers tend to require bigger tanks to be able to take into account the rainwater collection 333 systems in their management plans. Therefore water suppliers should advocate the use of indicators such as RI1, RI2 or RI3 and not only E for optimising the tanks' sizes so that they can diminish not only their operational costs but also their infrastructure costs. Nevertheless, 
336 listing and quantifying the savings are beyond the scope of this article and would require 337 further investigation.

\section{Conclusion}

In this paper, the reliability of the water provided by rainwater collection systems is

342 investigated for a housing estate. Indeed, if water suppliers are to take into account collection systems as a source of water in their management plan, it needs to have a certain level of reliability. The point of view of the water suppliers was adopted to define three indicators which have been assessed for 63 homogeneously distributed French cities. The main conclusions are:

- The three interesting indicators for the water suppliers are: the percentage of days the tank supplies $100 \%$ of the demand for WC flushing, the percentage of days the tank supplies 349 less than $10 \%$ of the water demand, and the percentage of water supplied by the tank secured $95 \%$ of the days of the simulation. The latter is the most relevant since it permits to exhibit the most disparities amongst the chosen cities.

- The optimum way of determining the storage capacity of the rainwater collection system is not the same if we adopt the point of view of the customers or if we adopt the water suppliers'. Indeed the water suppliers tend to require bigger tanks.

- Even if there are many disparities among the chosen French cities, it is possible to define five areas according to the reliability of the rainwater. It seems that France is stratified according to a direction South-West, North-East.

The only water demand taken into account in this paper is WC flushing. Studies involving other kinds of demands such as washing-machine demands are required. In this 
paper, the simulations are performed with daily rainfall time series of duration of five years.

362 Using a longer duration and smaller time step for the series would allow analysing the evolution of the indicators at a given location. On top of this, the consequences of climate

364 change could be investigated. Since water work systems are long term investments, this 365 aspect of the issue should be studied very carefully. Further investigation should be performed 366 to analyse the effect of sizing the tank from the viewpoint of the water suppliers. This would 367 consists in applying standard techniques such as the "percentage rate of change of an 368 indicator" (see Aquacycle users manual), not according to water saving efficiency as it is 369 usually done, but to the reliability indicators. Water suppliers are providing water to many kinds of urban areas. Therefore to fully 371 assess the potential infrastructure costs reduction due to rainwater collection; it would be 372 required to develop comparable models for urban areas other than housing estates. For instance investigation on heavily dense areas with high-rise buildings (here the roof areas are much smaller), or manufacturing district (high level of demand, and large potential roof areas) 375 should be carried out.

\section{$\underline{\text { Acknowledgments }}$}

We greatly acknowledge Cécile Huet (ENSG) for her help in drawing the maps with a 381 geographical information system, and Saskia de Longvilliers, Jean-Claude Deutsch and Bruno 382 Tassin for their advice.

\section{$384 \quad \underline{\text { References }}$}


C.I.EAU (Centre d'Information sur l'Eau), 2007, 54 questions pour “tout” savoir sur l'eau,

$$
\text { C.I.Eau }
$$

Coombes P. J., Argue J. R., KuCZera G., 1999, “Figtree Place: a case study in water sensitive urban development (WSUD)", Urban Water (1): 335-343

Coombes P. J. and KuCZera G., 2001, "Rainwater tank design for water supply and stormwater management", Stormwater Industry Association 2001 Regional Conference, Port Stephens, NSW

393 CoOmbes P. J., Barry M.E. 2007a, "The effect of selection of time steps and average assumptions on continuous simulation of rainwater harvesting strategies", Water Science and Technology, Vol 55, No 4, 125-133

COOMBES P. J., 2007b, "Energy and economic impacts of rainwater tanks on operation of regional water systems", Australian Journal of Water Resources, Vol 11, No 2, 177-1990

Cowden J., Watkins D. W., MihelciC J.R., 2008, "Stochastic rainfall modeling in West 399 Africa: Parsimonious approaches for domestic rainwater harvesting assessment", Journal of $400 \quad$ Hydrology, 361, 64- 77

401 De Gouvello B., Berthineau B., Croum I., François C., 2005, L'utilisation de l'eau de 402 pluie dans le bâtiment. Les résultats d'opérations expérimentales en France, Annales du 403 Bâtiment et des Travaux Publics (3) : 13-20.

404 FEWKES A., BUTLER D., 2000, "Simulating the performance of rainwater collection systems 405 using behavioral models", Building Services Engineering Research and Technology, 21(2): $406 \quad 99-106$

FEWKES A., 1999, "Modelling the performance of rainwater collection systems: towards a generalised approach", Urban Water (1): 323-333 
Ghisi E., MontiBeller A., SCHMidT R. W., 2006, “Potential for potable water savings by

410 using rainwater: an analysis over 62 cities in southern Brazil”, Building and Environment $411 \quad$ (41): 204-210.

412 GHISI E., 2006, "Potential for potable water savings by using rainwater in the residential 413 sector of Brazil”, Building and Environment (41): 1544-1550.

414 Herrmann Th., Schmida U., 1999, "Rainwater utilisation in Germany: eficiency, 415 dimensioning, hydraulic and environmental aspects", Urban Water (1): 307-316

416 Jenkins D., Paerson F., Moore E., Sun J.K., Valentine R., 1978, "Feasibility of rainwater 417 collection systems in California”, Contribution No. 173. Californian Water Resources 418 Centre, University of California

LuCAS S.A., COOMBES P.J., HARDY M.J., GEARY P.M., 2006, "Rainwater harvesting, revealing 420 the detail", Journal of the Australian Water Association, Nov 2006, 89-94

421 Mitchell, V.G., Mein, R., McMahon, T.A., 2001, "Modelling the Urban Water Cycle", 422 Journal of Environmental Modelling and Software, 16 (7) 615-629

423 Mitchell, V.G., Mein, R., McMahon, T.A., 2003, "UVQ: Modelling the urban Movement 424 of Water and Contaminants through the Total Urban Water Cycle", In $28^{\text {th }}$ International Hydrology and Water Symposium, 10-14 November, Wollongong, Australia

Mitchell, 2005, "Aquacycle user guide" Cooperative Research Centre for Catchment 427 Hydrology, http://www.toolkit.net.au/Tools/Aquacycle

428 NOLDE E., 2007, "Possibilities of rainwater utilisation in densely populated areas including 429 precipitation runoffs from traffic surfaces", Desalination, 215: 1-11. 


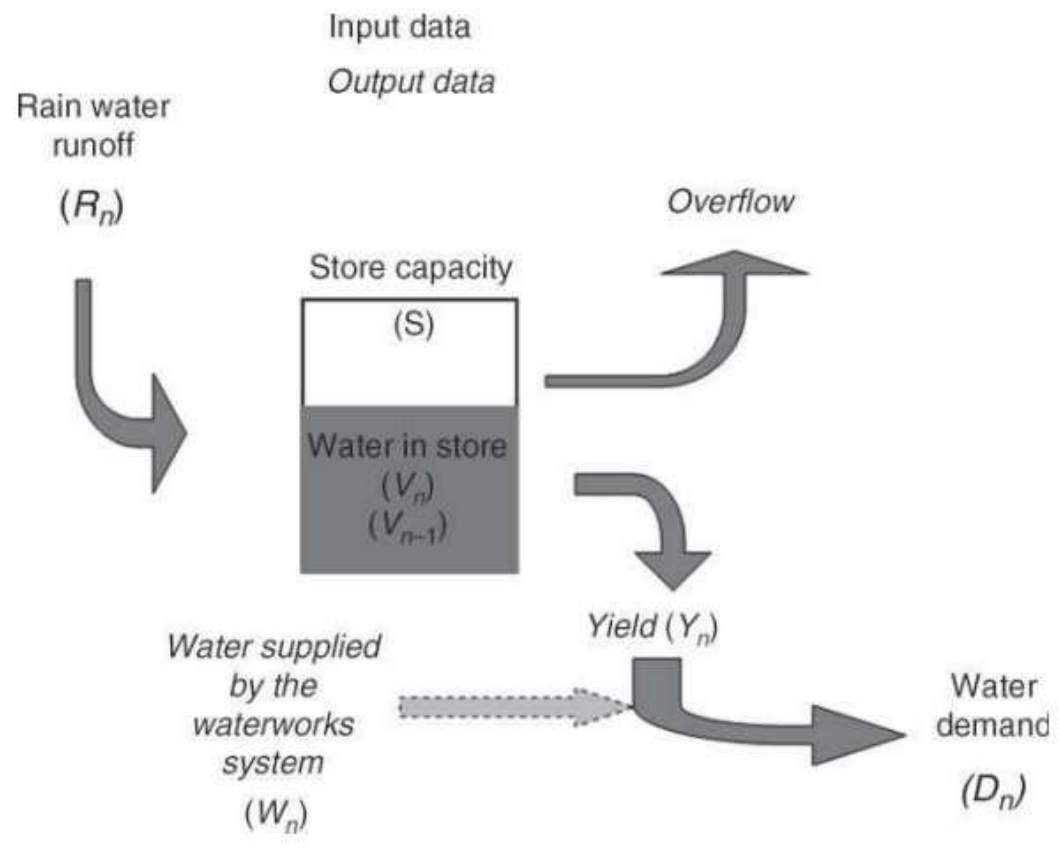

435 Fig 1: Description of a rainwater collection system

436

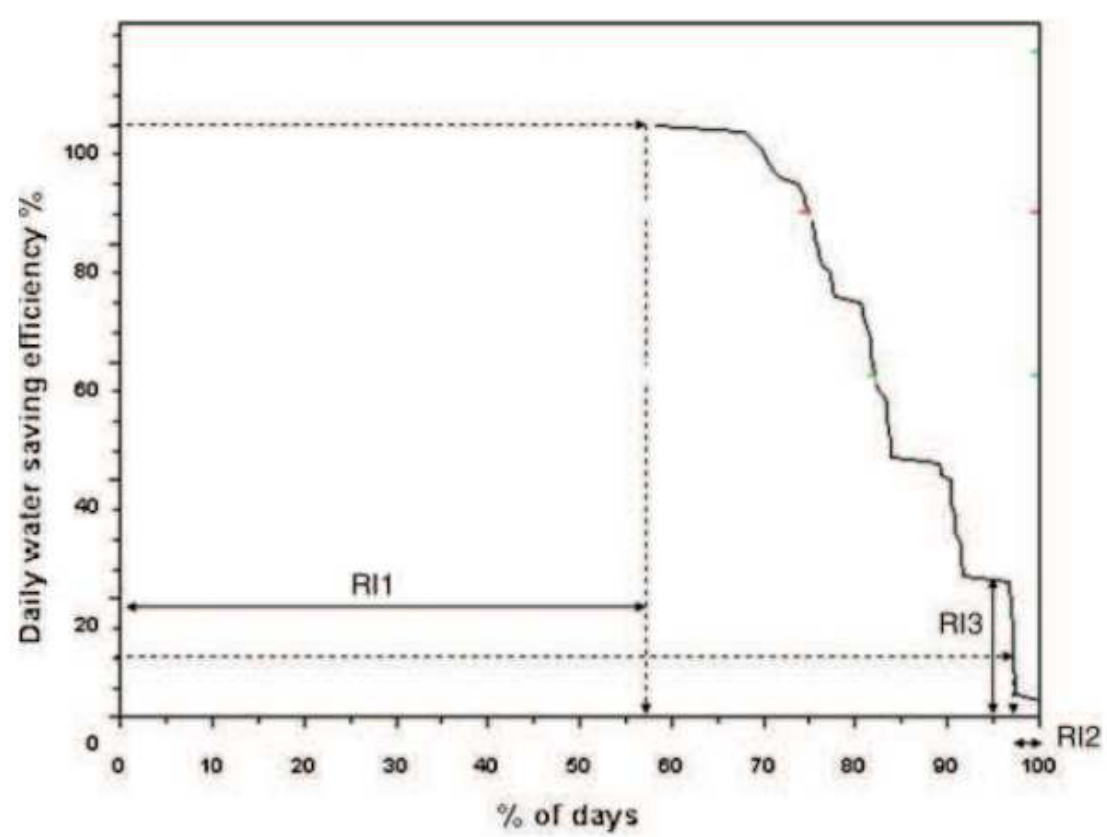

438 Fig 2: Example of a reliability curve for a simulation of a housing estate of 100 plots with the 439 population distribution of the couples option, a roof area of $110 \mathrm{~m}^{2}$ for all plots, a storage capacity of $1.3 \mathrm{~m}^{3}$ for all plots, and a rainfall series from Saint-Nazaire (West of France). 


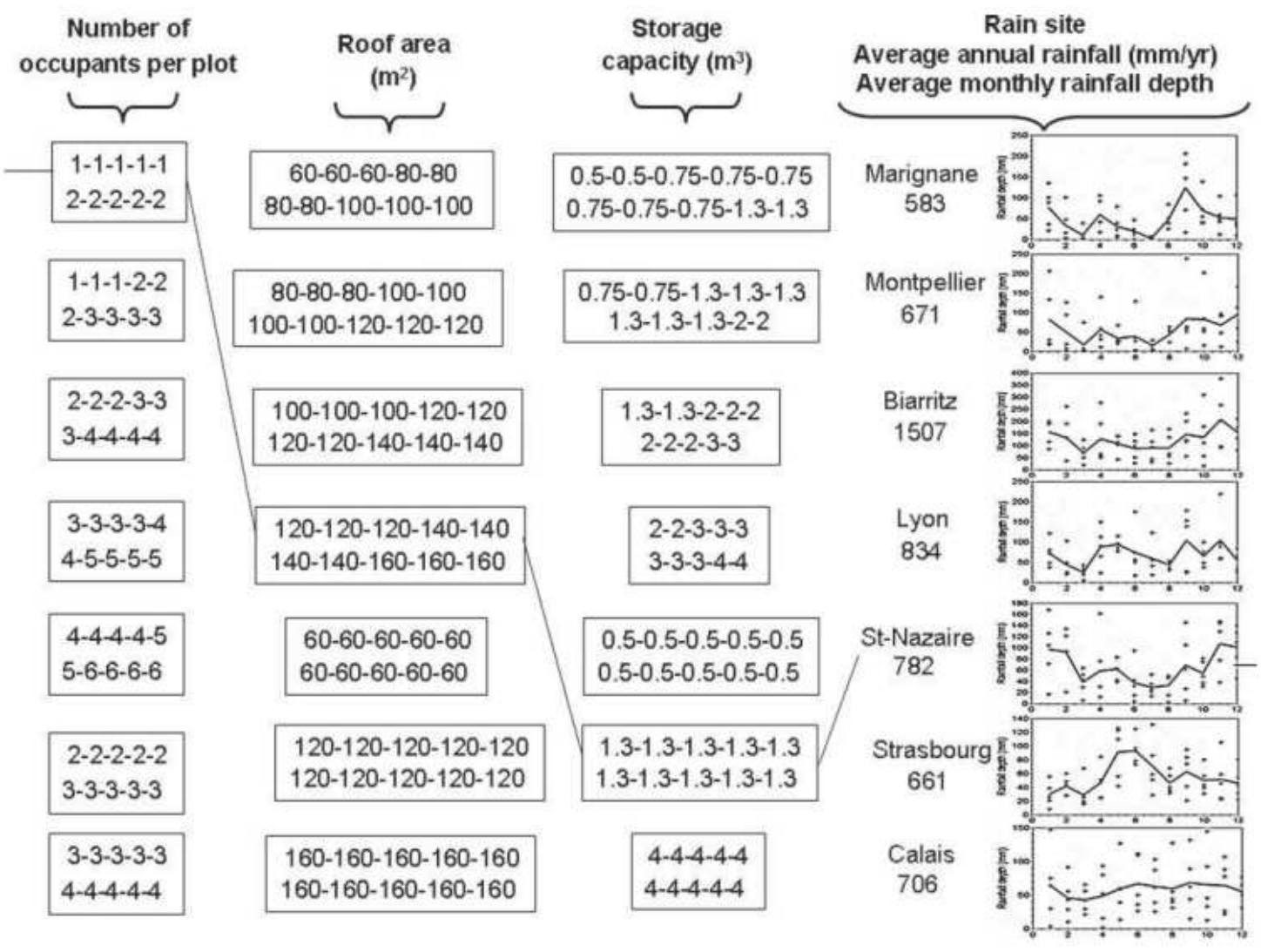

442 Fig 3: The chosen options to analyse the variability generated by each input. The modelled

443 housing estate consists of 10 plots. For each input, 7 options were defined, in turn defining

$4447 * 7 * 7 * 7$ scenarios. Defining a scenario consists in selecting one option for each input, as it

445 can be seen in the example. 


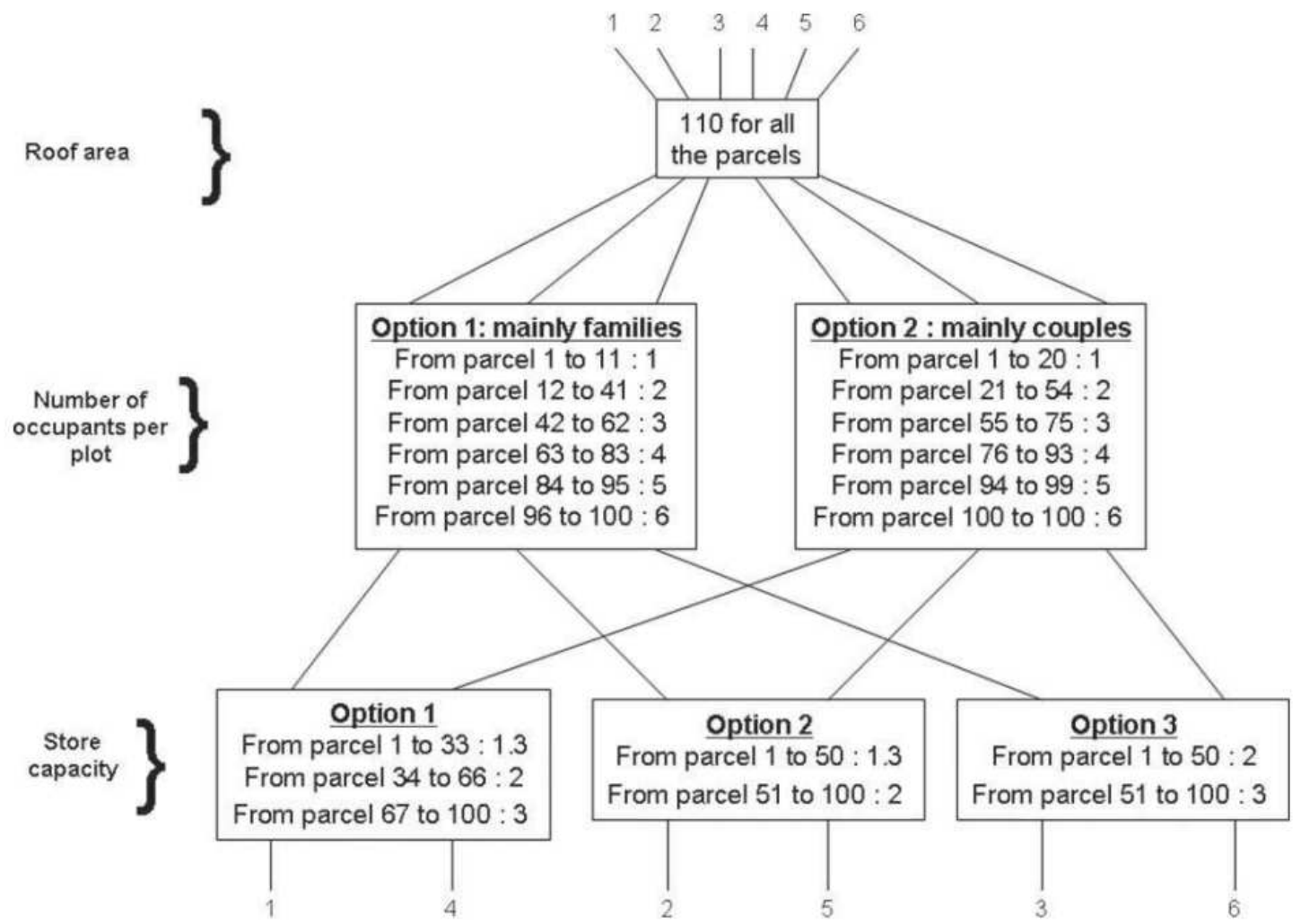

Fig 4: Definition of the chosen scenarios to perform the geographical analysis. The modelled

448 housing estate consists of 100 plots. Three options were defined for the storage capacity, one

449 for the roof area, and 2 for the number of people per plot. Therefore 6 scenarios $(=3 * 1 * 2 * 1)$

450 were considered for each city. The dash represents a scenario. 


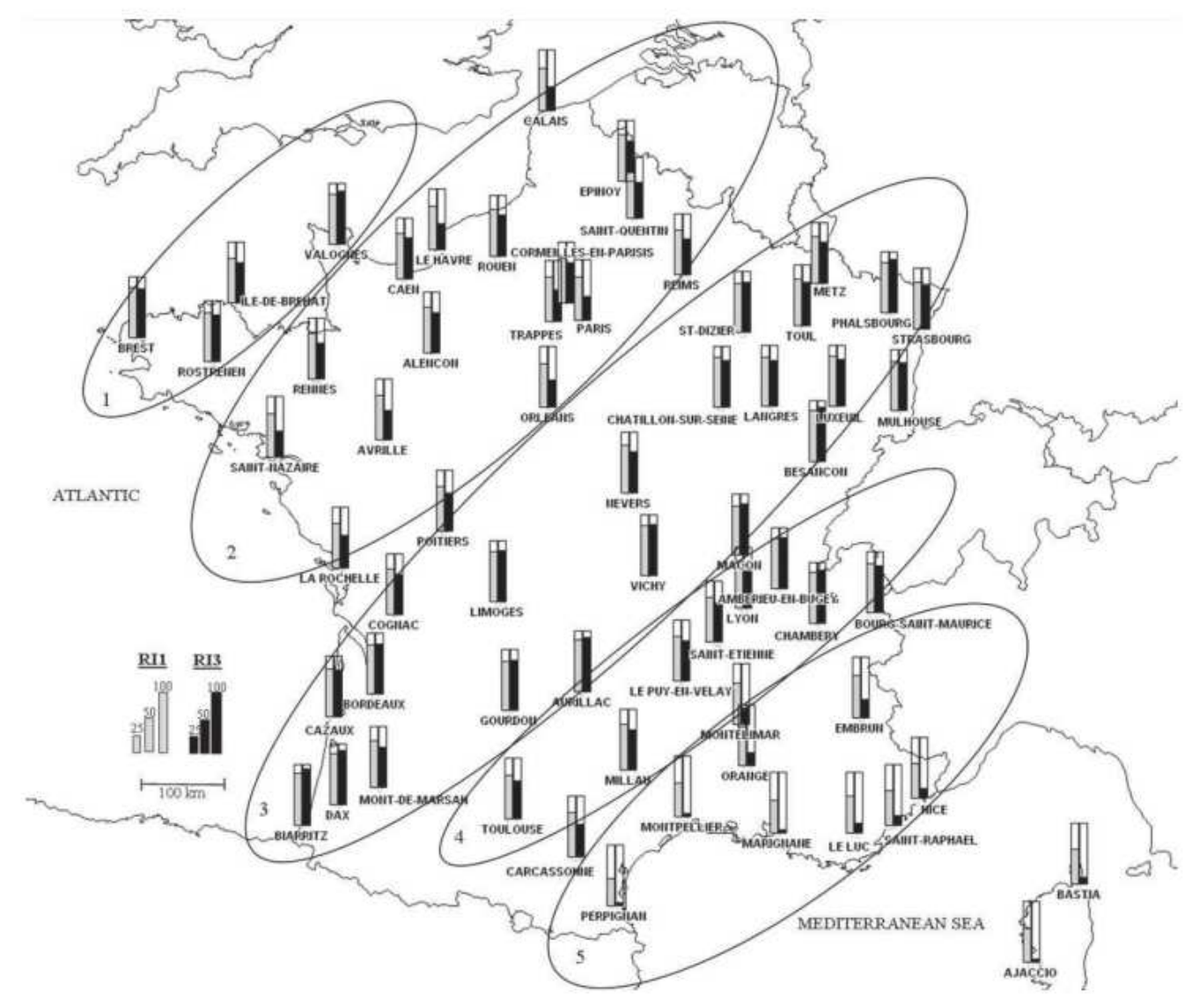

Fig 5: The RI1 indicator (the percentage of days the tank supplies $100 \%$ of the demand for 454 WC flushing) and the RI3 indicator (the percentage of water supplied by the tank being 455 secured for $95 \%$ of the days of the simulation) for 63 French cities. Five main areas are also 456 represented.

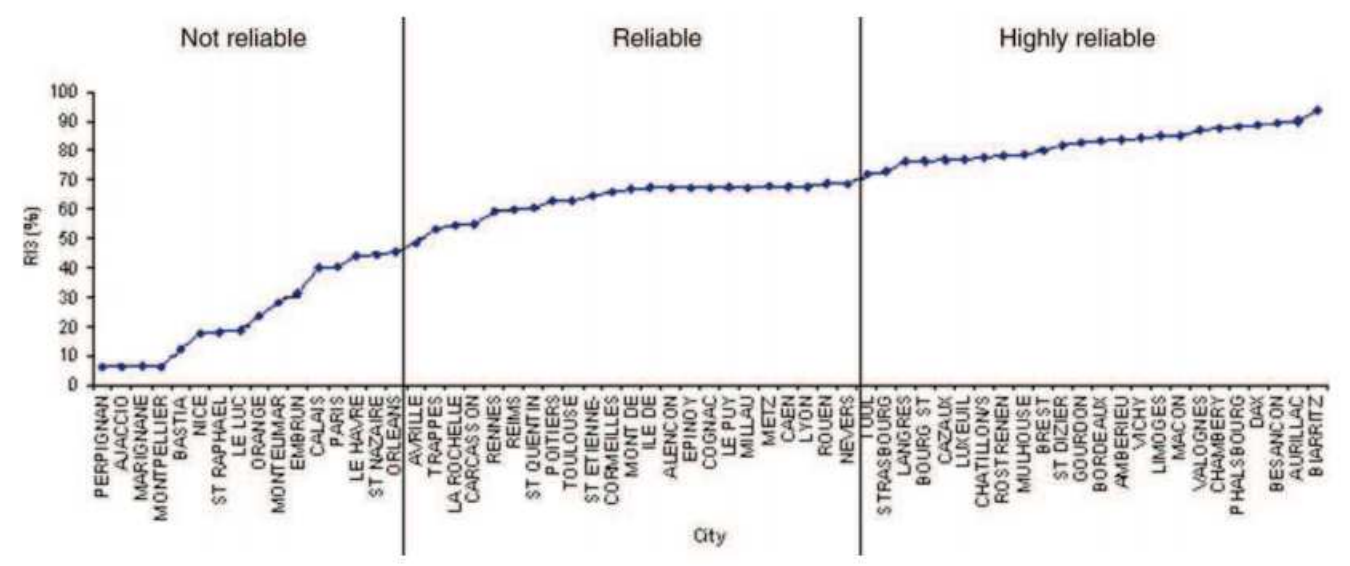

458 Fig 6: RI3 versus the cities (which have previously been sorted in order according to increasing value of RI3), and the definition of three clusters of cities 


\section{Tables:}

462

463 Table 1 : Distribution of the occupants according to the plot of the two considered options for 464 the repartition. The mainly families option corresponds to the city of Vendeville (North of 465 France), whereas the mainly couples option corresponds to the city of Ge ' ne 'mos (South of 466 France). Both cities are looking like a housing estate. (The figures are coming from the 1999 467 INSEE census of the French population)

470 The houses

$471 \quad$ Number of houses

$472 \%$ of individual houses

473 The occupants

$474 \%$ of house with 1 people

$475 \%$ of house with 2 people

$476 \%$ of house with 3 people

$477 \%$ of house with 4 people

$478 \%$ of house with 5 people

$479 \%$ of house with 6 people or more 5.3

481 Table 2 : Variability generated by each input on the different indicators

482 Input

$\begin{array}{llll}\text { E } & \text { RI1 } & \text { RI2 } & \text { RI3 }\end{array}$

483 Rain

$\begin{array}{llll}30.8 & 28.0 & 32.4 & 24.9\end{array}$

484 Occupants

$\begin{array}{llll}6.6 & 11.9 & 5.7 & 19.1\end{array}$




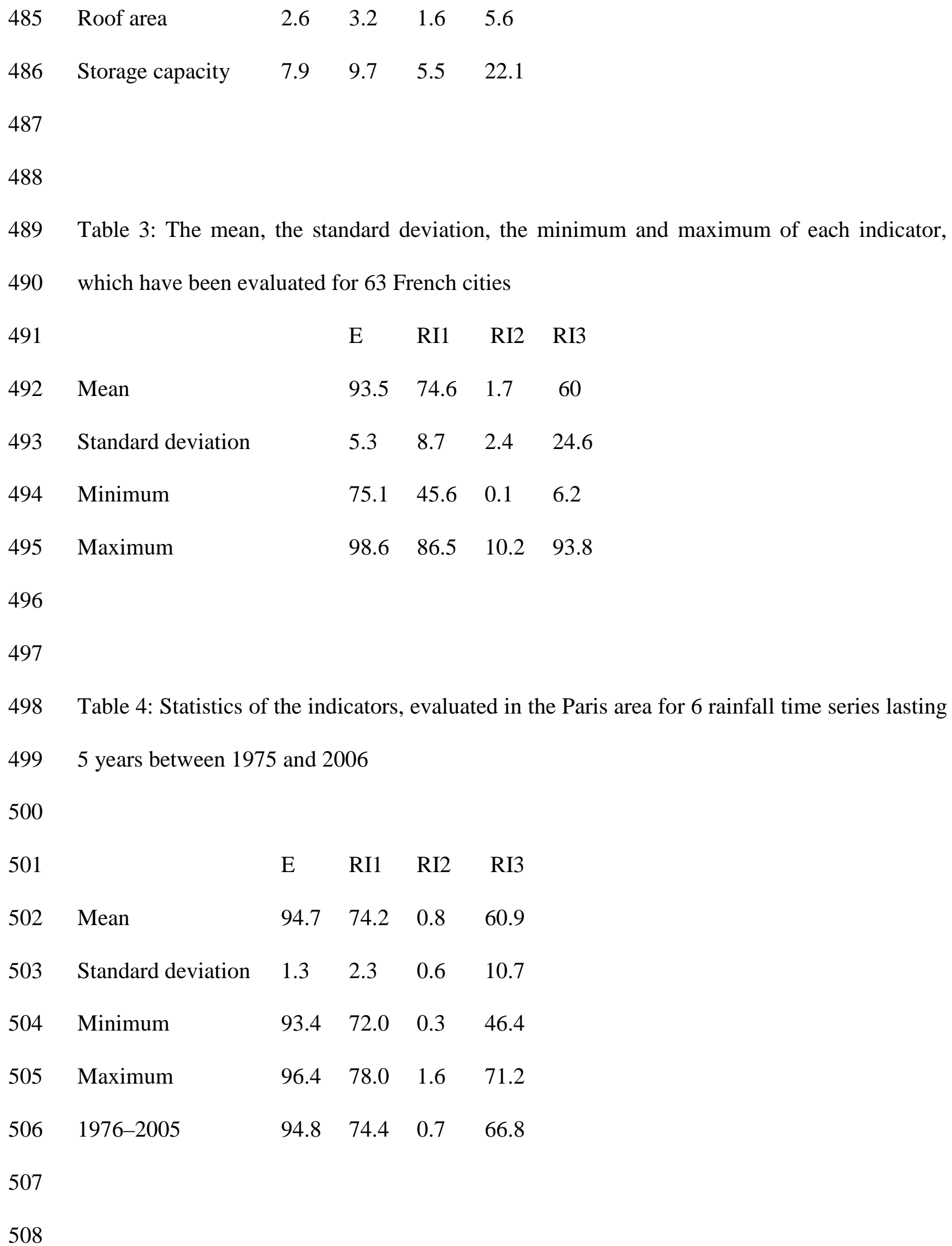

